\title{
Excavations in the Uattamdi rockshelters, Kayoa Island
}

\author{
Peter Bellwood, Rachel Wood, Geoffrey Irwin, and Agus Waluyo
}

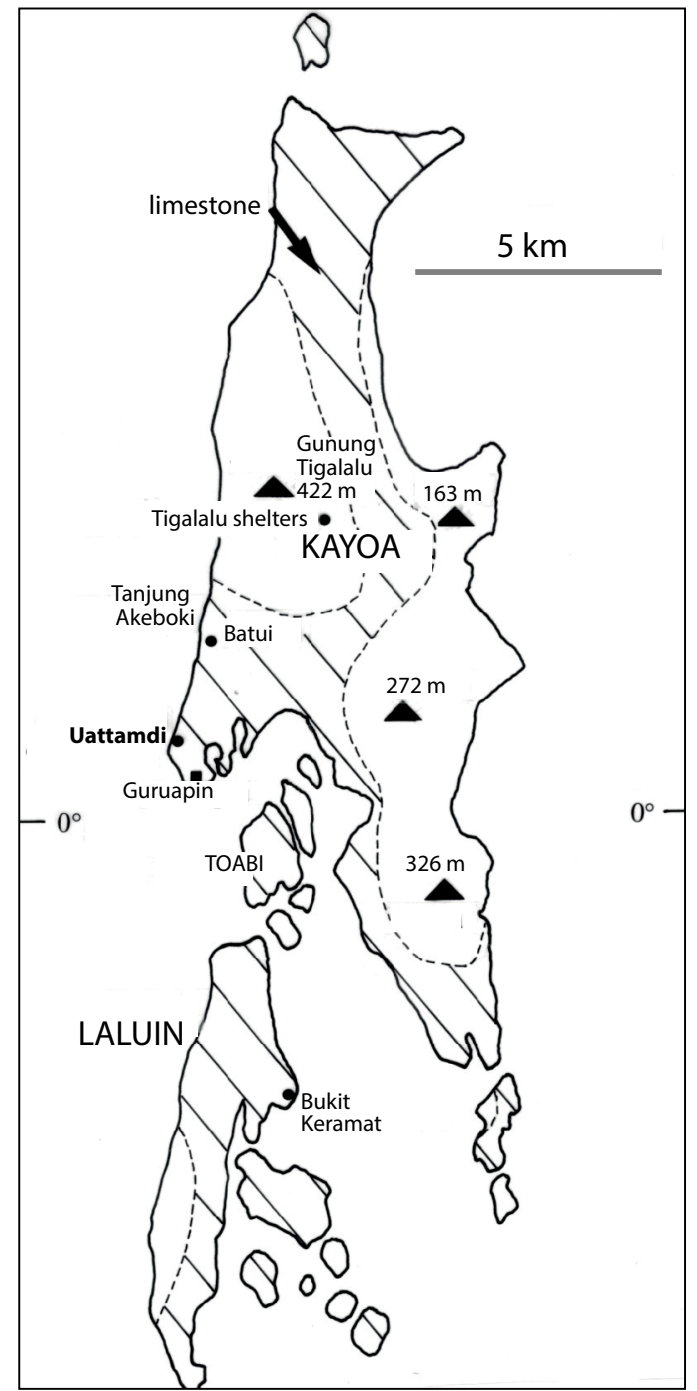

Figure 5.1 Map of Kayoa.

Diagonally shaded areas are uplifted coral limestone. Source: Peter Bellwood.
The island of Kayoa, with neighbouring Laluin and Toabi, lies about $30 \mathrm{~km}$ off the western coast of the main island of Halmahera, equidistant between the volcanic islands of Makian to the north and Bacan to the south, and within the volcanic inner arc that van Bemmelen (1949:48) termed the Ternate Zone. It is about $20 \mathrm{~km}$ long by a maximum of $7 \mathrm{~km}$ wide (Fig. 5.1). Unlike the other volcanic islands, which lie to its north (especially Makian, Moti, Tidore and Ternate), Kayoa is low-lying and volcanically inactive. The highest point, Gunung Tigalalu at $422 \mathrm{~m}$, is an ancient eroded volcano that still retains a definite volcanic skyline with an inner cone and outer crater rim. According to the map in Hall et al. (1988: Fig. 6), the Tigalalu volcanic rocks could be as recent as Late Pleistocene in age. Parts of eastern Kayoa consist of pre-Miocene volcanics. However, most of the island, apart from the discrete volcanic zones, is formed from uplifted Pleistocene reef limestone.

Kayoa is a slightly tilted island, with a zone of raised coral along much of its western coastline, this zone also extending southwards along the west coast of the neighbouring island of Laluin immediately to the south. A rather drowned and estuarine topography with extensive mangrove swamps lies along the eastern shoreline of both islands. Western Kayoa has coral sand beaches and coral headlands, with a series of at least three levels 
of raised coral reef, visible as interrupted low cliffs, lying at increasing altitudes inland. The shelter complex of Uattamdi lies in the lowest of these coral cliffs just to the north of the headland of Tanjung Pompom, $1.5 \mathrm{~km}$ north of the equator. It can be reached by walking trail from the town of Guruapin, the administrative centre for the kecamatan of Kayoa.

\section{Uattamdi 1}

The main excavated shelter of Uattamdi 1 (henceforth U1: Figs 5.2, 5.3) is located in the low cliff (here about $6 \mathrm{~m}$ high) of raised coral, which lies about $60 \mathrm{~m}$ inland from the head of the beach. Between the shelter and the beach is a flat coastal plain, today planted under coconuts, that lies at the same level as the floor of the shelter. The shelter thus has no raised deposits within, and indeed its floor is completely flat to the exterior, with a habitable area of about $50 \mathrm{~m}^{2}$. In conditions of heavy rain, drips form at various places in the shelter roof, which has a fairly cracked and crumbly appearance, causing the excavation team to cast wary eyes aloft from time to time. But in general the conditions within are dry. The roof of the shelter is about $3 \mathrm{~m}$ high.

It should be mentioned here the modern shelter floor lies approximately $1.5-2 \mathrm{~m}$ above modern high tide level. Furthermore, the base of the cultural deposits lies about $1.2 \mathrm{~m}$ below the modern shelter surface on a sterile surface of beach sand (denoted below as Layer E). This beach sand within the shelter thus lies at the same absolute level as the modern beach. This point is stressed here because it indicates that, since occupation began in the shelter about 3500 years ago, there has been no local relative movement of sea level, at least not along this particular stretch of coastline. In this respect, the local sea level history at Uattamdi apparently differs from that at Buwawansi on Gebe, discussed above. At Buwawansi, sea level at 4000 BP was perhaps $1 \mathrm{~m}$ higher than now according to the record in Buwawansi shelter 3. Because of the likelihood of a eustatic sea level drop of approximately $1 \mathrm{~m}$ between 4000 and 3500 BP in Southeast Asia generally (Sathiamurthy and Voris 2006), these variations at Uattamdi and Buwawansi perhaps reflect local tectonic rather than regional eustatic movements.

The situation of basal beach sand Layer E also indicates that, at c. 3500 BP and just prior to human occupation, the active beach was within the shelter and the modern coastal plain did not exist. Presumably, this plain has developed as a result of inland soil erosion and coastal deposition since occupation in the site began. As in many Pacific islands (e.g. Kirch and Yen 1982 for Tikopia; Carson 2014 for Guam), this circumstance could reflect the environmental impact of the introduction of an agricultural economy to the island.

Uattamdi 1 was the first site to be excavated in the Moluccan program. In the 1990-91 excavation period, the 1x1 m squares D4 to D9 were excavated, followed by $\mathrm{C} 4$ to $\mathrm{C} 7$ and $\mathrm{E} 4$ to E9 in 1994 (Fig. 5.3). These squares, in total, cover $10 \mathrm{~m}^{2}$, excavated to the culturally sterile beach sand Layer $\mathrm{E}$ at an average depth of $1.2 \mathrm{~m}$. The square labelled AB7 in Figure 5.3 was not excavated since the deposits here were heavily concreted with calcium carbonate from the shelter wall. Deposits were sieved through 2.5 or $3 \mathrm{~mm}$ meshes and excavation was carried out in $5 \mathrm{~cm}$ spits within the five major layers in the site, these being lettered from Layer A (at the top) to the pure beach sand Layer $\mathrm{E}$ at the base of the site. 

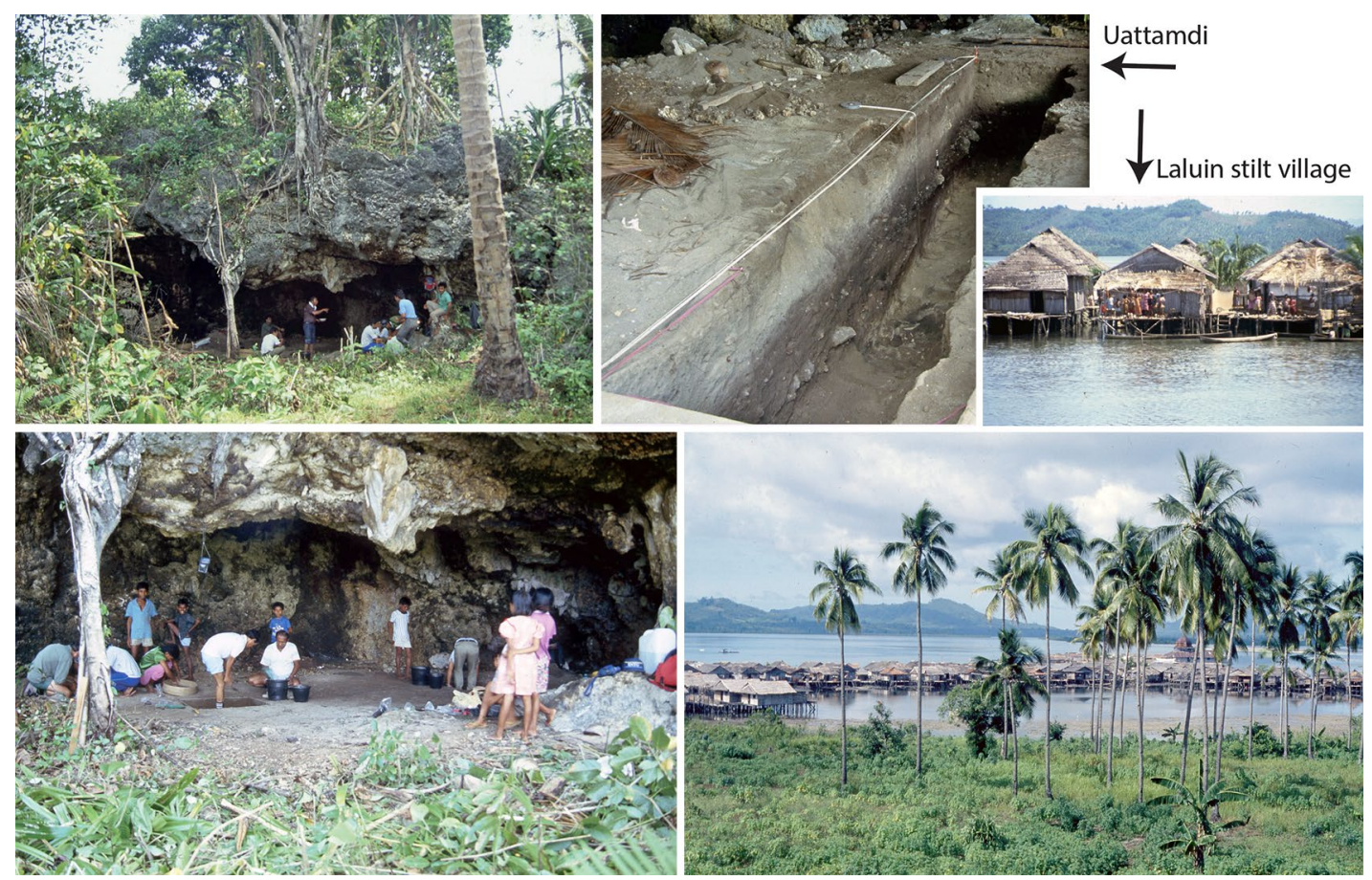

Figure 5.2 Uattamdi 1 photos.

Left and top: Uattamdi rockshelter 1, situated in a cliff of raised coral limestone, and the east wall of trench D4-D9 dug in 1991. At right, the Bajau stilt village immediately offshore from the Bukit Keramat site (see Chapter 6) on Laluin, photographed in 1991. Source: Peter Bellwood.

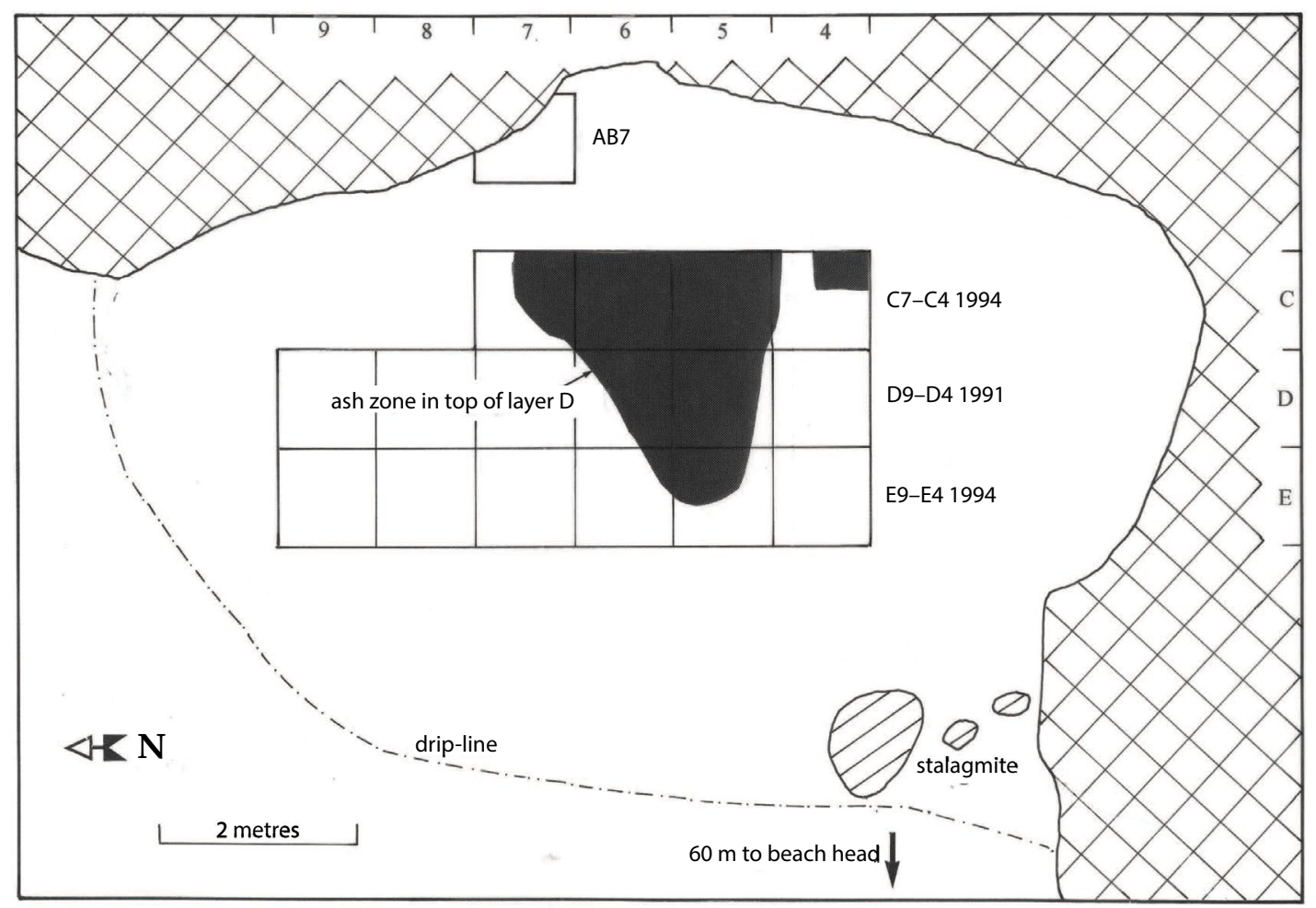

Figure 5.3 Uattamdi 1 site and excavation plan.

Source: Peter Bellwood. 
The five layers in the site (Fig. 5.4) are all very sandy and clearly derive basically from a coral beach sand matrix. Simple observation suggests that they are either fairly pure beach sand (Layers $\mathrm{E}$ and $\mathrm{B}$ ) or are beach sand mixed with soil from the local environment plus the debitage of human behaviour (Layers D, C and A). Grain size analyses indicate that all layers comprise over 80 per cent sand, with the most silt/clay-rich being Layer $\mathrm{C}$, the richest in traces of human activity. The coarse components of each layer, after separation, are identical in visual appearance, being simply stained coral beach sand. The five layers can be described as follows, based on the section drawing in Figure 5.4, starting from the bottom:

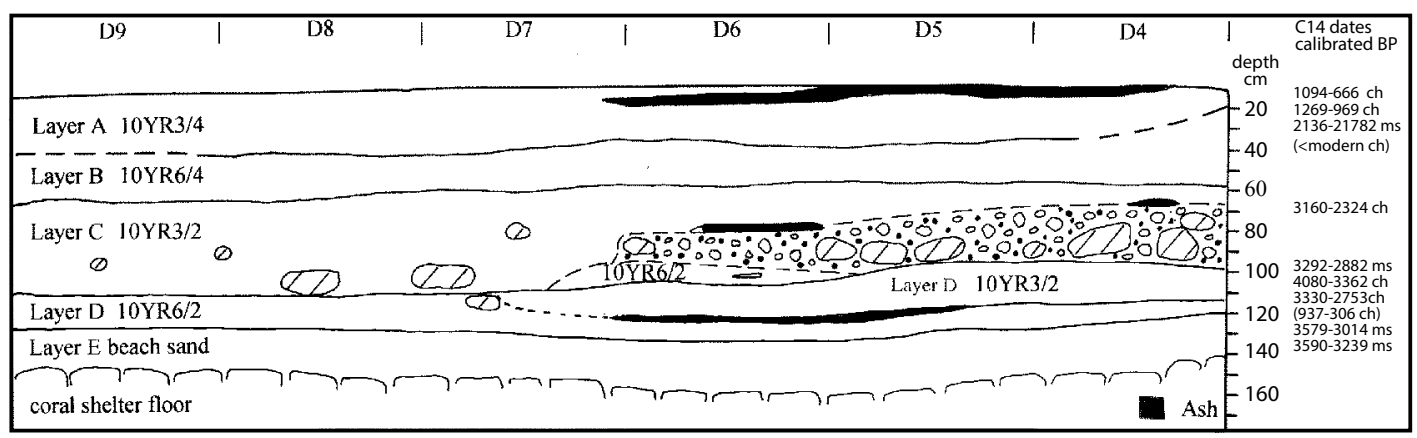

Figure 5.4 Uattamdi 1 section, Squares D4 to D9, east wall.

C14 dates are listed in Table 1.1 (ch = charcoal, ms = marine shell).

Source: Peter Bellwood.

Layer E: This is pure coral beach sand, identical to the modern beach. It contains weathered marine shells, from which the date of 3590-3239 cal. BP (ANU 9321) has been derived. Layer E is pre-human, and careful examination of it in cross-section suggests that it already had a thin veneer of dark topsoil, perhaps washed in from behind and above the shelter, before occupation began. Soil can be seen washing in during heavy rain from the south side of the shelter today. This veneer of topsoil is identified as Layer D below, and suggests that human occupation began sometime after the sea had retreated on a fairly reliable basis from the shelter. Layer $\mathrm{E}$ is only about $20-30 \mathrm{~cm}$ thick and sits directly on the coral rockshelter floor. The shelter was presumably wave-cut in origin, like many that can be seen in formation in coral headlands along the modern west coast of Kayoa, and has a fairly flat coral floor beneath the sediments. It can also be noted here that $\mathrm{U} 1$ has no traces of any preceramic occupation.

Layer D: This layer can be described as beach sand mixed with soil, giving a dark deposit that ranges from light yellowish-brown to very dark greyish-brown in colour. As just noted, the lighter-coloured part started life as the topsoil over the beach sand Layer E, into which the cultural material deposited by the first occupants of the site became trodden. Layer D has a sharp interface with the beach sand Layer $\mathrm{E}$ beneath. The main activity in Layer $\mathrm{D}$ was the creation of an extensive but quite thin ash deposit from hearths, as shown in Figure 5.3. This lies on the upper surface of the primary old topsoil portion of Layer $\mathrm{D}$, but at the southern end of the trench these hearths are covered by a 10-15 cm deposit of dark greyish-brown soil (labelled 10YR3/2 in Fig. 5.4). It is not clear whether this extensive ash represents one large episode of activity or many superimposed small ones, but the absence of hearths elsewhere in the excavated part of Layer D suggests that the time involved in deposition could have been quite short.

The C14 dates for Layer D actually cover quite a large time span, from 4080 to $2753 \mathrm{cal}$. BP (Fig. 5.5). However, it seems most unlikely that Layer D could represent continuous activity over 1000 years, and a commencement date after 3579-3014 cal. BP based on ANU 7776 is supported by the pre-human Layer E marine shell date of 3590-3239 cal. BP (ANU 9321), 
as discussed above. The Bayesian chronological model (Fig. 5.5) identifies two dates within Layer D as outliers at more than 10 per cent probability. The youngest ANU 9320 is clearly too young, and is more similar in age to material from Layer A, despite being on charcoal from hearth features. ANU 10959, again on charcoal, is slightly too old, which could be a result of the old wood effect. The Bayesian model therefore suggests that Layer D dates between 3516-3058 and 3285-2769 cal. BP (start and end probability ranges given at 95 per cent probability).

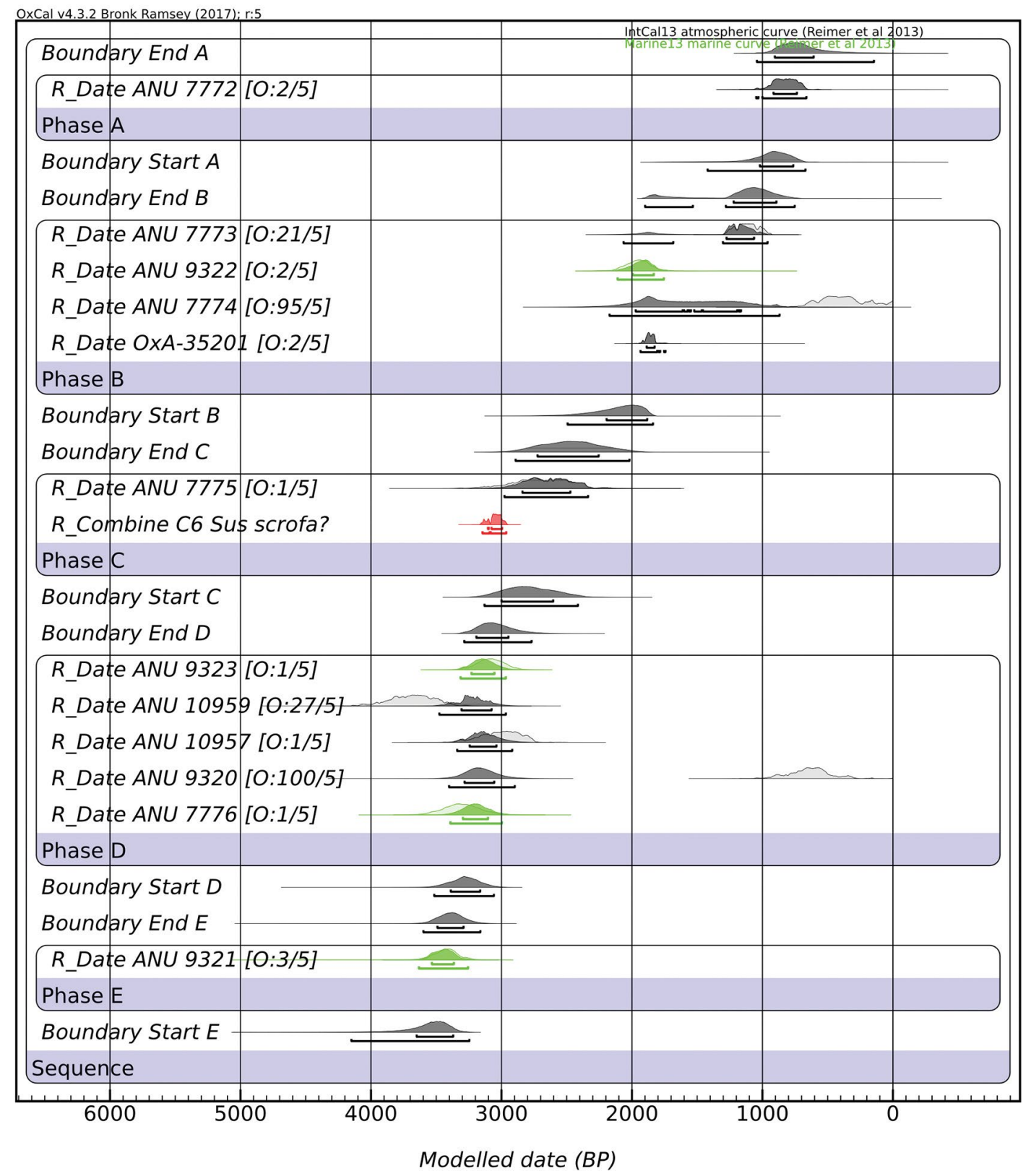

Figure 5.5 A Bayesian chronological model for Uattamdi produced using 0xCal v.4.3 (Ramsey 2009).

Pale distributions denote the calibrated ages, and dark distributions the modelled ages. The two lines beneath the probability distributions represent the 68 per cent and 95 per cent probability ranges. Prior and posterior outlier probabilities are given next to the date name. Dates are calibrated against IntCal13 (grey) or Marine13 (green) (Reimer et al. 2013) with a $\Delta R$ of 0. All dates have been assigned a prior probability of 5 per cent within the General t-type Outlier Model, except for S-ANU 60005 (red), which is excluded from the model and only shown for reference due to the known problems with radiocarbon dates on tooth enamel. Details of C14 dates are listed in Table 1.1.

Source: Rachel Wood. 
Layer C: This layer is a very dark greyish-brown sandy soil, within which there is a very dense layer of coral rubble, presumably derived from roof-fall, across the southern side of the trench (Figs 5.4 and 5.6). Layer $\mathrm{C}$ has one $\mathrm{C} 14$ date, of 3160-2324 cal. BP (ANU 7775), on ash likely to have contained charcoal from a hearth in spit C3, Square D7. This fits well within the general sequence of dates from the site and supports an overall date range for Layer $\mathrm{C}$ somewhere between c. 3000 and $2500 \mathrm{cal}$. BP. Two further radiocarbon dates on tooth enamel from a single M2 of a Sus scrofa mandible found in spit C6 are slightly older than ANU 7775 and similar to the age of charcoal in unit D at around 3150$2890 \mathrm{cal}$. BP. No collagen was preserved in the mandible or tooth dentine and a radiocarbon date on enamel was attempted. Radiocarbon dates on tooth enamel are notoriously unreliable, and often underestimate the true age of a sample by hundreds of years in the Holocene as groundwater carbonate is difficult to remove (Hedges et al. 1995; Grün et al. 1997; Zazzo 2014). This tooth was subjected to two pretreatment methods in an attempt to remove as much contamination as possible. Wood et al. (2016) suggested that unless enamel was heavily recrystallised, most contaminating carbonate is likely to sit at the crystal boundaries within the enamel, and they found that age increased if the sample was mechanically crushed before cleaning with acetic acid. Radiocarbon dates on finely ground Pleistocene enamel were still too young, but in the late Holocene they were indistinguishable from their known age. Dates on the tooth enamel from Uattamdi 1 do not agree with this finding, with the handground sample (S-ANU 60005, 2928 \pm 29 BP) giving an age indistinguishable from that of the mechanically ground sample (S-ANU 60006, $2884 \pm 35 \mathrm{BP}$ ). However, this tooth enamel was extremely soft and crumbly, and has an FTIR PCI (Phosphate Crystallinity Index) of around 5.0, higher than modern Sus scrofa teeth with PCIs typically around 4.8 (data not shown). Combined with the radiocarbon result, this suggests that recrystallisation had occurred. Although the date is unlikely to be accurate, it does broadly agree with its stratigraphic position.

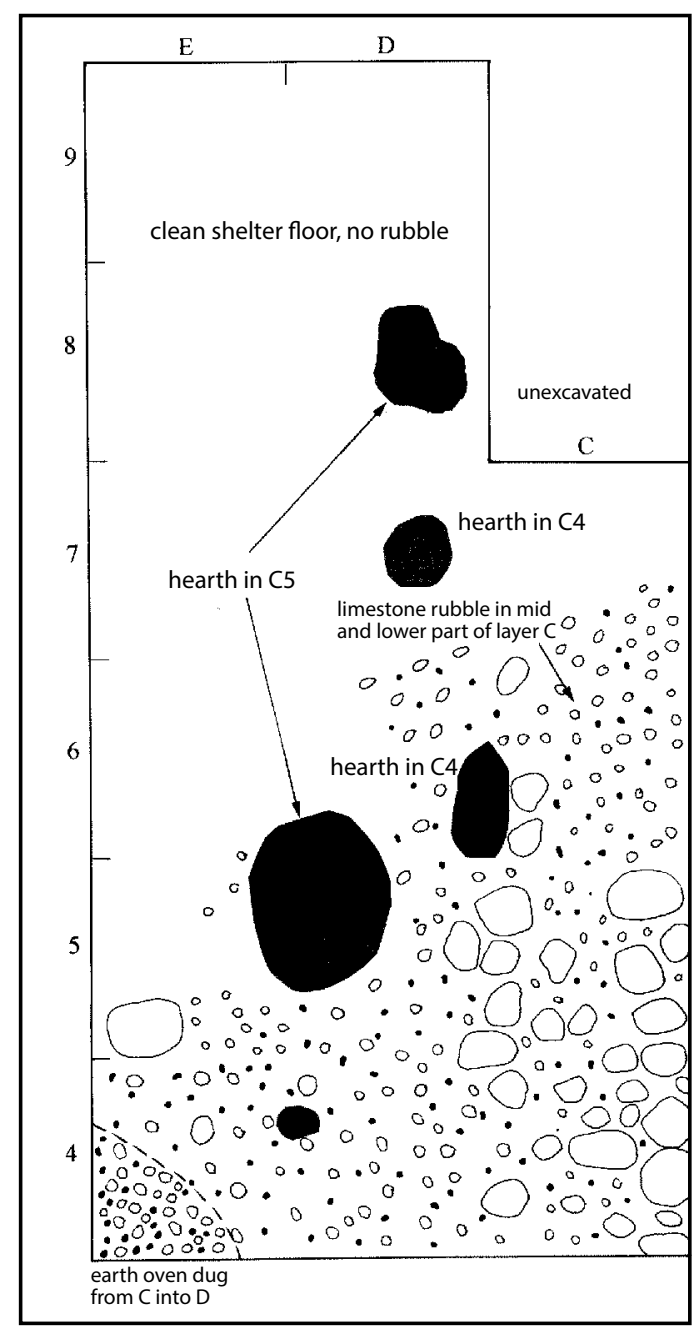

Figure 5.6 Hearths over limestone roof fall in Uattamdi 1, Layer C.

Source: Peter Bellwood.

U1 seems to have been occupied fairly frequently during the period represented by Layer C, but one major event represented in the southern part of the excavation was the appearance of the band of coral rubble mentioned above, some of very large rocks, presumably derived from an episode of roof fall. Because no rubble occurs in the northern part of the trench, and because the rubble is of even thickness, it gives the suggestion of having been piled neatly away from the major occupation area to the front (north) of the shelter. Sherds occur throughout the rubble, but presumably fell in while it was still loose and without soil matrix. Layer C immediately above the roof fall contains a number of hearths, shown in Figure 5.6. An earth oven 
with volcanic stones was also cut into Layer D in Square C4 from some point in Layer C, the exact point being rather hard to determine. Layer $\mathrm{C}$ has a very clear separation from Layer $\mathrm{B}$ above, but the limited number of dates from Layer B that fit the Bayesian model makes it impossible to ascertain if there was a temporal separation between the two.

Layer B: This layer is fairly pure, but slightly humic-stained coral beach sand, light yellowishbrown in colour. It was very clearly defined in the trench sections and contains many pieces of sea-borne pumice, probably resulting from the entry of a high sea (tidal wave?) into the shelter caused by an eruption with associated earthquake activity of one of the local volcanoes (Makian being the closest). There is no historically recorded eruption that fits this scenario, and Layer B was presumably deposited prior to the two C14 dates on a human cranium and marine shell (OxA 35201 and ANU 9322, respectively, see Table 1.1) that cover a 95.4 per cent range from 2136 to $1782 \mathrm{cal}$. BP. It is possible that this apparently cataclysmic event caused a local abandonment of the region for a while. This, at least, could be suggested by the cultural stratigraphy, which passes from pre-metal in Layer $\mathrm{C}$ to unequivocally Early Metal Phase in Layers $B$ and $A$, with associated rather sharp changes in ceramic style.

Layer B had a relatively low density of cultural material compared to Layer C, and it is apparent that the shelter passed from being a zone of habitation to being a zone of burial after its deposition. Layer B contained many glass beads, pieces of metal and large burial jar sherds (see Table 5.1), all derived from jar burials, which were perhaps laid on the floor of the shelter or perhaps dug into shallow pits from the Layer B/A interface. Many of the glass beads will undoubtedly have worked down the profile by themselves, but in Squares E7-E8, six large burial jar sherds were found in obvious association at the B2 level, perhaps from the base of a smashed burial jar placed on the former shelter surface at this level. Sitting directly on top of two of the sherds and in direct touching contact with them was a complete Turbo marmoratus shell, a large reef gastropod that surely had some special function apart from food. This shell gave the C14 date ANU 9322 referred to above, which calibrates to c. $2000 \mathrm{BP}$. The jar burial assemblage thus presumably dates from this time, with burial activity perhaps continuing towards ANU 7773 at $1094-666 \mathrm{cal}$. BP. Many small pieces of human bone were also found in Layer B, with a partial cranium buried upside-down (Fig. 11.8), presumably in a shallow pit, in Square E4, spit B4. This cranium has been directly radiocarbon dated to $1932-1813 \mathrm{cal}$. BP (OxA 35201, 95.4\%, OxCal 4.2). Layer B also has traces of occasional postholes cut into it, but no coherent plan could be traced.

Layer A: This is the sub-modern surface layer of the site, dark yellowish-brown in colour. On the modern surface are extensive ash deposits, which informants say come from sea salt evaporation activities undertaken within living memory. Otherwise Layer A, which dates to within the past 1000 years, has only a low density of cultural material, much perhaps disturbed upwards from the layer of jar burial activity at the interface between Layers A and B. It is worth noting here that shelter U1 has no sherds of the ethnographic style of pottery from Mare Island (Pulau Mare; see Mahirta 2000), and so has not been used for domestic activities for several centuries. Pulau Mare style pottery does, however, occur in the seaward shelter U2, discussed below.

\section{The vertical distribution of material culture within Uattamdi 1}

The artefact categories from Uattamdi 1 will be dealt with in more detail in later chapters, but at this point it is necessary to look at distributions through time with respect to the dated layers described above. This can be done by examining Figure 5.7 and Table 5.1. To an extent, the data are self-explanatory, but some points require emphasis. Indicators of occupation intensity in $\mathrm{U} 1$ are shown in Figure 5.7. In these, the data given are raw weights by layer, uncorrected to take account of layer thickness (i.e. they are quantities, not densities). In order to convert them to densities it is necessary to bear in mind that Layers A, B, C, and D are related volume-wise 
in ratios of approximately 4:4:7:4 respectively (i.e. A, B, and D are much the same in volume, while $\mathrm{C}$ is 75 per cent bigger). But even taking density into account it is obvious that volcanic cooking stones (upper chart) are most frequent in the occupation Layers $\mathrm{C}$ and $\mathrm{D}$, and rare in the burial Layers A and B. Likewise, food shell and animal bones (middle chart) are most frequent in Layer C. So too is pottery (lower chart), which shows an interesting bimodal distribution, with the Neolithic red-slipped ware accounting for the stratigraphically deeper peak and the Early Metal Phase jar burial pottery accounting for a much smaller peak in Layer A3. Incidentally, this chart does not include the large and very heavy burial jar sherds, which would, of course, skew the results so much as to make them almost meaningless.

One may also note the sharp differentiation between a Neolithic (stone and shell) assemblage in Layers C and D, and a Early Metal Phase assemblage with a wide range of components in Layers A and B (Table 5.1). The glass beads that occur in upper Layer $\mathrm{C}$ appear to cross the divide, but in this case movement downwards must surely be the answer. This division is very marked and seems to fall around 2000 BP (ANU 9322) or later. Layers A and B contain all the metal, human bone, and burial jar sherds recovered from the site. Layers $\mathrm{C}$ and $\mathrm{D}$ contain all the stone tools, shell ornaments, and virtually all the red-slipped pottery.

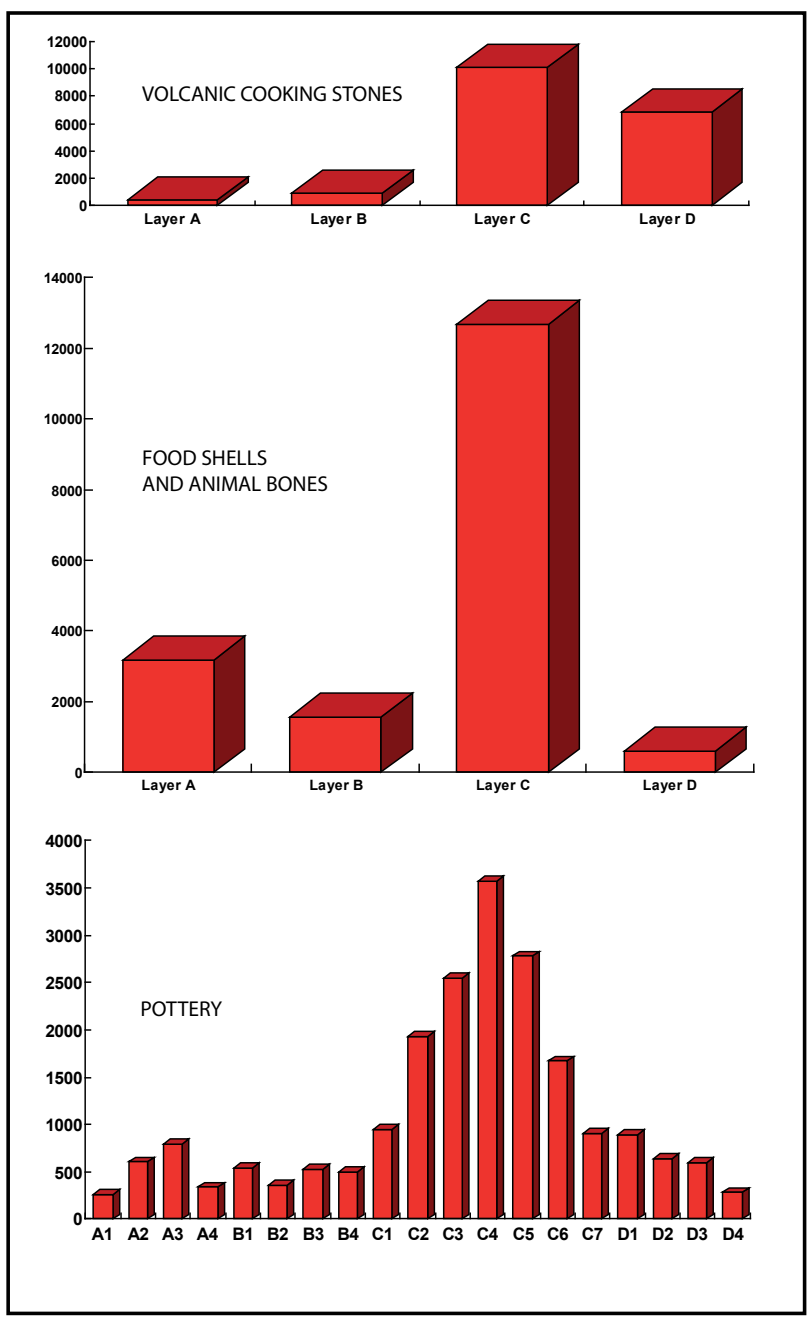

Figure 5.7 Uattamdi 1: vertical distributions of cooking stones, food shell and animal bone, and pottery sherds (excluding the jar burial vessels shown in Fig. 7.5).

Vertical axis shows weights in grams, horizontal axis shows Layers A to D.

Source: Peter Bellwood. 


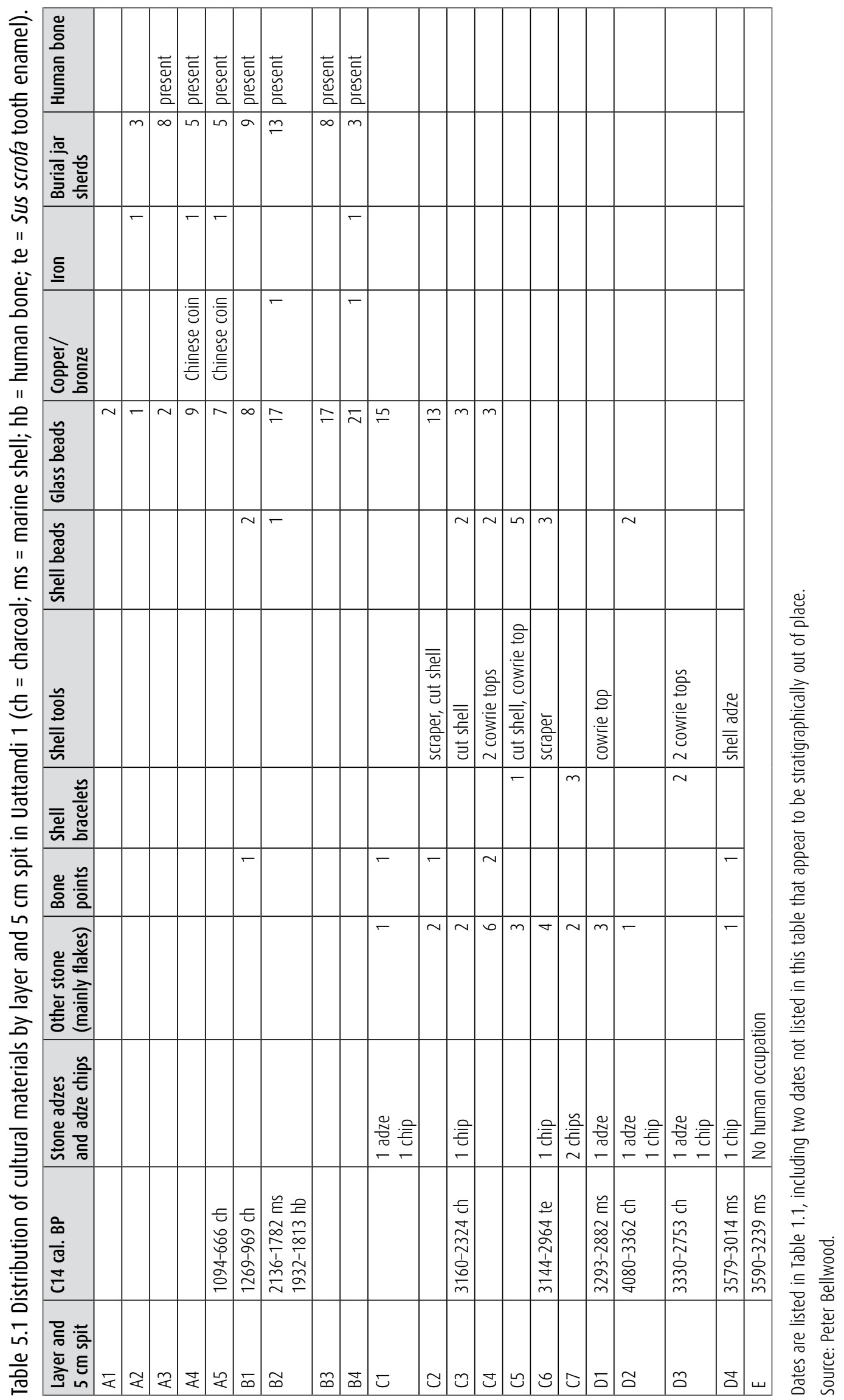




\section{Uattamdi 2}

This shelter lies $75 \mathrm{~m}$ west-southwest of Uattamdi 1, beneath a large block of uplifted coral that runs to the modern beach. Its surface is level with the top of the modern beach and the site is only $17.5 \mathrm{~m}$ inland, thus much closer to the sea than U1. This means, of course, that it is only likely to contain young archaeological deposits. A $1 \times 1 \mathrm{~m}$ square was laid out in the middle of the c. $16 \mathrm{~m}^{2}$ floor area of the shelter. This yielded a cultural layer only $30 \mathrm{~cm}$ thick, over sterile beach sand. The pottery from the shelter surface and from the cultural layer was all of the modern red-slipped and burnished Pulau Mare type (Mahirta 2000), so it is clear that this shelter does not contain deposits which are more than one or two centuries old. 
This text is taken from The Spice Islands in Prehistory: Archaeology in the Northern Moluccas, Indonesia, edited by Peter Bellwood, published 2019 by ANU Press, The Australian National University, Canberra, Australia. 